Research Article

Open Access

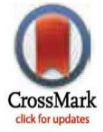

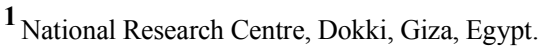

2 Al Guthami Foundation, Saudi Arabia.

3 Ministry of Health, Egypt.

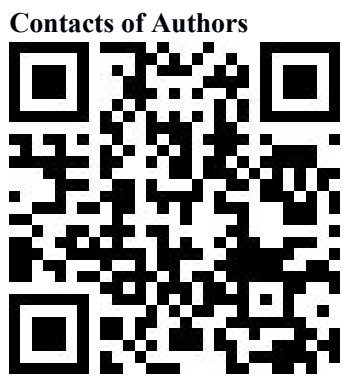

To whom correspondence should be addressed: Ahmed G. Hegazi

Citation: Ahmed G. Hegazi, Faiz M. Al Guthami, Mohamed H. Basiouny, Ahmed F.M. Al Gethami (2020). Topical Saudi Arabia Talh honey (Acacia nilotica) on surgical wound healing activity. Highlights in BioScience Volume 3. Article ID 20220. dio:10.36462 /H.BioSci.20220

Received: June 6, 2020

Accepted: August 18, 2020

Published: September 10, 2020

Copyright: (C) 2020 Hegazi et al. This is an open access article distributed under the terms of the Creative Commons Attribution License, which permits unrestricted use, distribution, and reproduction in any medium, provided the original author and source are credited.

Data Availability Statement: All relevant data are within the paper and supplementary materials.

Funding: This study was financially supported by the National Research Centre, Giza, Egypt, with a grant no. 11020201 and Al Guthami Foundation, Saudi Arabia.

Competing interests: The authors declare that they have no competing interests.

\section{Topical Saudi Arabia Talh honey (Acacia nilotica) on surgical wound healing activity}

\author{
Ahmed G. Hegazi ${ }^{1 *}$, Faiz M. Al Guthami ${ }^{2}$, Mohamed H. Basiouny ${ }^{3}$ and Ahmed \\ F.M. Al Gethami ${ }^{2}$
}

\section{Abstract}

Honey has been documented as the oldest traditional medicine. It has been effective in suppressing inflammation, wound repair enhancer, and rapid autolytic debridement. The aim of this investigation was to evaluate the role of Saudi Arabia Talh honey (Acacia nilotica) dressing as a good alternative in care of diabetic foot (DFU) healing activity for twenty patients, wound total bacterial count, and serum cytokines levels (IFN- $\gamma$, IL-1, and IL-6). The results showed that Talh honey stimulates the wound healing process, broad-spectrum antibacterial activity, and reduction in the proinflammatory cytokines IFN- $\gamma$, IL-1, and IL-6 levels. It could be concluded that Talh honey bioactivities enhance wound healing by promoting tissue growth leading to wound repair, antibacterial, and reduction of inflammation.

Keywords: Honey, wound healing, cytokines, total bacterial count.

\section{Introduction}

One of the emerging options is the honey dressing due to a variety of bioactive compounds found in honey [1], which has broad-spectrum bactericidal effects [2], reduces inflammation and promotes debridement [3], immune cell activation [1] and reducing bad odor [4]. Using the topical application of honey in superficial and partial thickness burns was performed to compare film and gauze-based dressings [5]. Brölmann et al., [6] found that honey was effective in dressings, local debridement therapy, effective in reducing wound healing time and systemic antibacterial therapy. The main reasons for morbidity in particular, diabetic patients referred to, foot ulcers, which reached $50 \%$ of non-traumatic amputations. Also, the management of diabetic foot ulcers is an important integral part of wound dressing [7].

Improve health and spur economic growth are the heart of Sustainable Development Goals (SDGs). Therefore, to induce these improvement uses the natural products. The randomized clinical study required one of the best alternatives natural products as honey to compare in wound care and a variety of existing topical agents. Previously, some clinical trials reported to evaluate honey effects in wound healing, particularly diabetic foot ulcers. Therefore, this study aimed to determine the role of Saudi Arabia Talh honey (Acacia nilotica) in the diabetic foot (DFU) wound care as a dressing with a good alternative in treating advanced wounds. 


\section{Materials and Methods}

\section{Ethical approval}

All experimental procedures were carried out under Protocol No. 20072, in accordance with the guidelines of the National Research Centre, Dokki, Giza, Egypt.

\section{Experiment Design}

Twenty patients from General Surgery out clinic, this study was conducted. It was a 3-year, prospective, RCT which was started from 2018 to 2020 . The data collection and pro forma were filled either by the patient or relatives. All patients $\geq 18$ years of age were selected for this study with postoperative wound, diabetic foot ulcer. Diabetic foot ulcer patients: Ankle Brachial Pressure Index (ABPI) < 0.7, uncontrolled diabetes i.e. HbA1c $>7 \%$, hemoglobin $10 \mathrm{~g} / \mathrm{dl}$ also, local signs of infection were the presence of pus and culture-positive were included. The subjects were divided into two groups (ten each). The first group was treated with fresh acacia Talh (Acacia nilotica) while the second group treated with conventual treatment. To remove debris, the wound was washed before dressing with usual saline and patients were admitted to the hospital for at least the first 2 dressings, protective dressing was sealed with the second layer and depending on the wound condition the dressing was done once or twice daily for each day, where the dressing was done by doctor or nursing staff as a dressing procedure in the out-clinic. According to the situation, loading was done by using special full-boot cast, or shoes, or crutches. When required debridement of the wound was done. It was performed in the outpatient department under local anesthesia or without anesthesia if the patient did not feel pain.

The Visual Analog Scale [8] was performed for evaluation of wound healing activity. Complete healing of the wound was the primary outcome. While the secondary outcomes were considered as the satisfaction of patients', side effects of dressing methods and healing time, side effects of dressing methods, signs of local or systemic infection deterioration of wound. Up to 120 days or earlier if the wound was healed, all participants were monitored. Complete epithelialization, no discharge, and wound closure were considered to be wound healing.

Under aseptic condition swaps were taken from the wounds for bacterial examination was performed. The serum cytokines (IFN- $\gamma$, IL-1, and IL-6) levels were evaluated before and after treatment.

Acacia Talh (Acacia nilotica) honey (30 kg), 2018 flowering season was kindly provided by Alnahal aljwal Company, Saudi Arabia. The physiochemical analysis was performed according to Hegazi et al., [9]. The consideration of fresh monofloral honey was performed as described by Louveaux et al., [10]. Honey was stored at $2-8^{\circ} \mathrm{C}$ in a sterile glass container until used.

\section{Laboratory Analysis}

Determination of bacterial count (CFU): Under aseptic condition swabs from wounds were taken. These swabs were incubated in $10 \mathrm{ml}$ of nutrient broth at $37^{\circ} \mathrm{C}$ for 24 . Then 10 -fold serial dilutions of the homogenates in the nutrient broth were cultured, in duplicates dilutions were cultured on neomycin blood agar using $100 \mu \mathrm{l}$ of the diluted specimen for each plate [11]. Plates were incubated for $24-48 \mathrm{~h}$ at $37^{\circ} \mathrm{C}$ on $5 \% \mathrm{CO}_{2}$. By using a colony counter, the bacterial colonies were counted as the method described [12]. The colonies of isolated bacteria were confirmed microscopically and biochemically as described in the method of [13].

Serum cytokine levels: At before and after treatment at the end of the study interleukin (IL) $1 \beta$, IL- 6 , and IFN- $\gamma$, were assessed using sandwich ELISA [14]. The serum cytokines levels were measured by using commercially available ELISA kits according to the manufacturers' directions (kits purchased from Biovision Co., China).

\section{Statistical analysis}

The results reported in this study have been interpreted as a means \pm standard error, and analyzed using variance analysis (ANOVA). Samples were analyzed using Student's t-test (two-tailed) for unpaired samples with equal variance using Excel (Microsoft, Seattle, WA). Using the Duncan Multiple Range Test, the significance of the difference between mean values at $\mathrm{P}<0.05$ was calculated.

\section{Results}

In this study, honey has been used to treat with a number of chronic, acute, infected, or badly colonized wounds. The latter wounds, however, remained free of infection, and displayed no further deterioration. All patients required systemic antibiotics. It was noted that showed honey within 24 hours has a rapid cleansing and deodorizing action also reduced inflammation and exudate levels particularly on fungating (malignant) wounds (Figure 1).

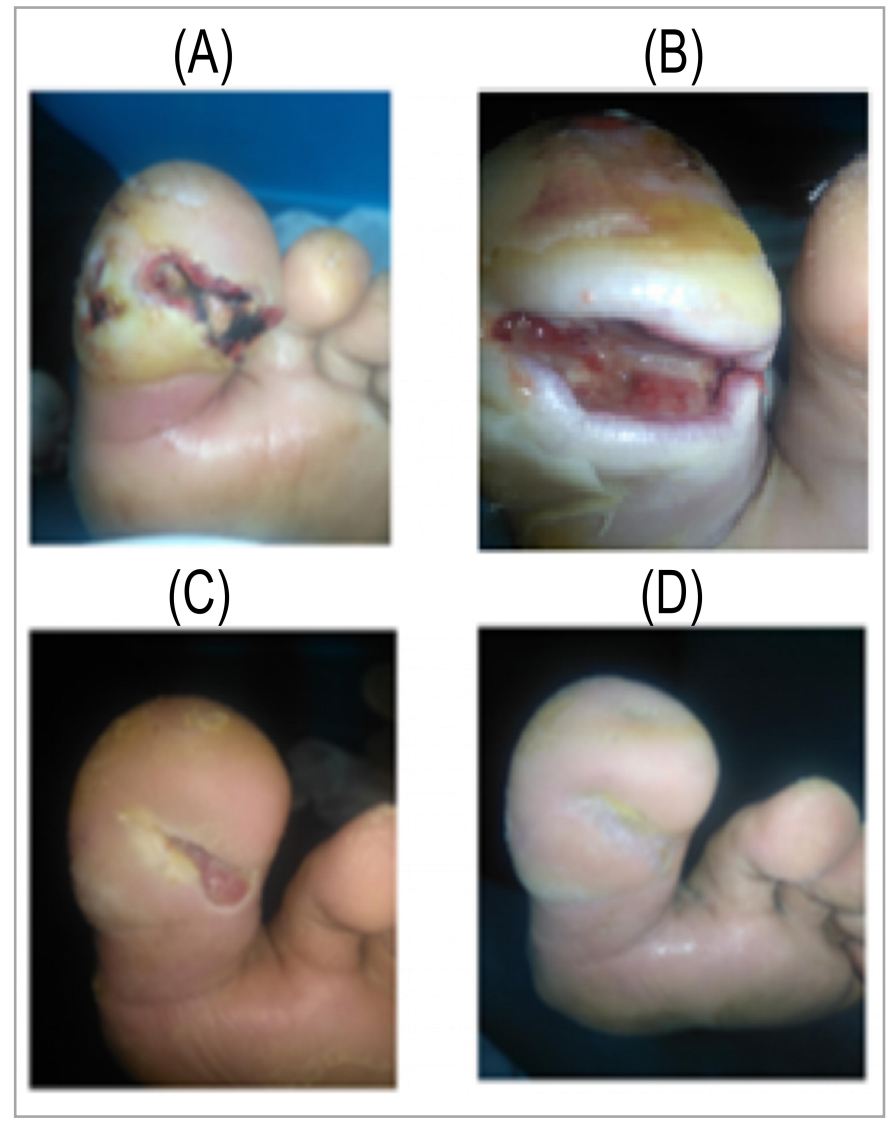

Figure 1. Randomized controlled trials of honey. (A) gangrenous part of wet type of diabetic foot need to mechanical debridement. (B) Wound with little necrotic tissue after dressing by honey. (C) Wound decrease in size. (D) wound covered by skin and crustation. 
The following randomised controlled honey experiments showed good results as compared with other dressing strategies: (1) Honey compared to povidone-iodine, (2) Honey compared to povidone-iodine with $70 \%$ ethanol washes on extreme post surgical wound infections, and (3) Honey compared to regular methods such as normal saline with glycerin amnesia or creams (mebo, iruxol, panthenol).

\section{Quantification of patient's sera cytokines}

Honey therapy demonstrated a substantfigurial change in immunological status as a result of a decline in inflammatory serum cytokines (Figure 2). It was clear that there was a significant $(\mathrm{p}<0.05)$ reduction in serum, IFN- $\gamma$ $(-12 \%)$, IL1 $\beta(50 \%)$, and IL6 $(-55 \%)$ relative to the corresponding pre-treatment values.

\section{Evaluation of the antibacterial activity of Saudi Arabia Talh honey (Acacia nilotica)}

The investigations of this microorganism during this study indicated that the isolated bacteria were characteristic by numerous short, thick, straight, round-ended, cocci Gram-positive, and Gram-negative identified in agar plates used for subculture. The total bacterial count was $8 \times 10^{9}$ at the begging of the experiment then it reduced after the application of traditional therapy to $\left(9 \times 10^{4}\right)$ while honey treatment reached to $\left(9 \times 10^{2}\right)$ after 17 th days post-treatment as shown in Figure 3.

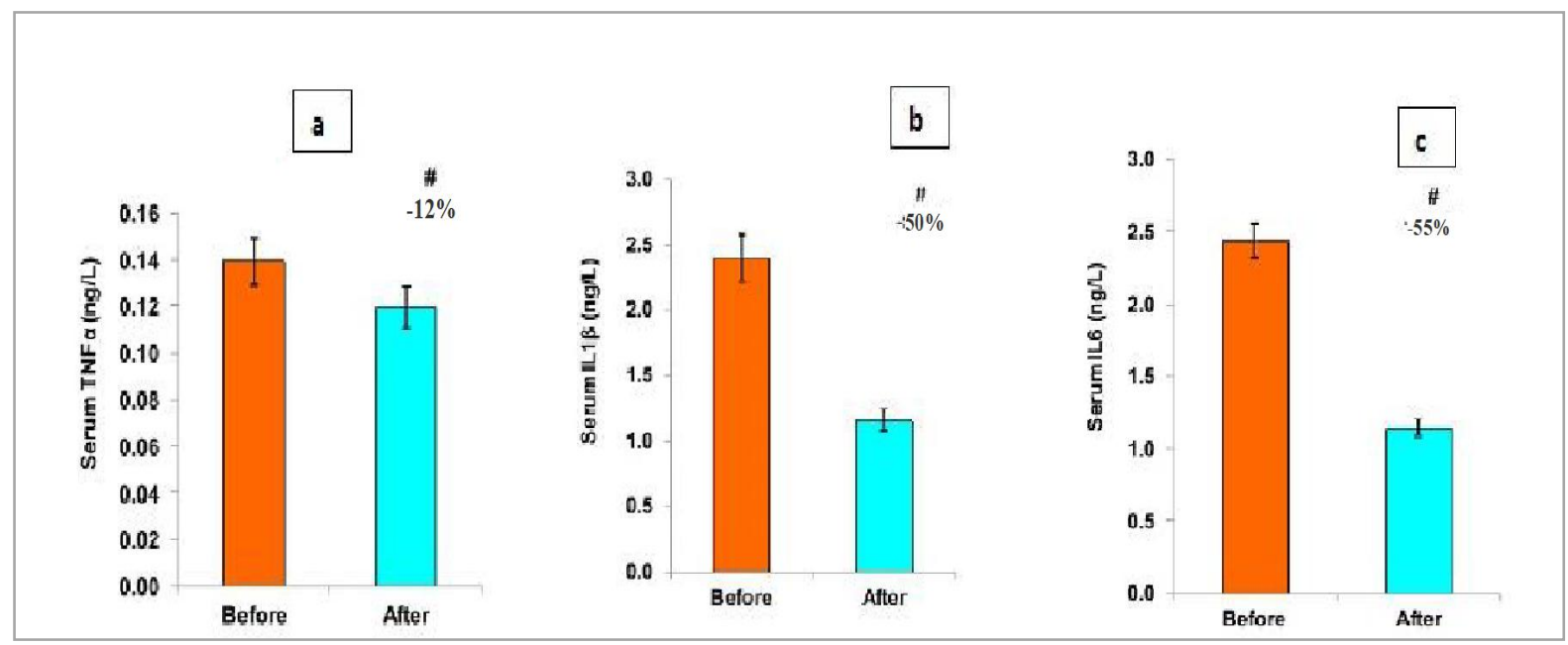

Figure 2. The effect of the honey treatment on patients serum level of (a) IFN- $\gamma$, (b) IL1 $\beta$, and (c) IL6.

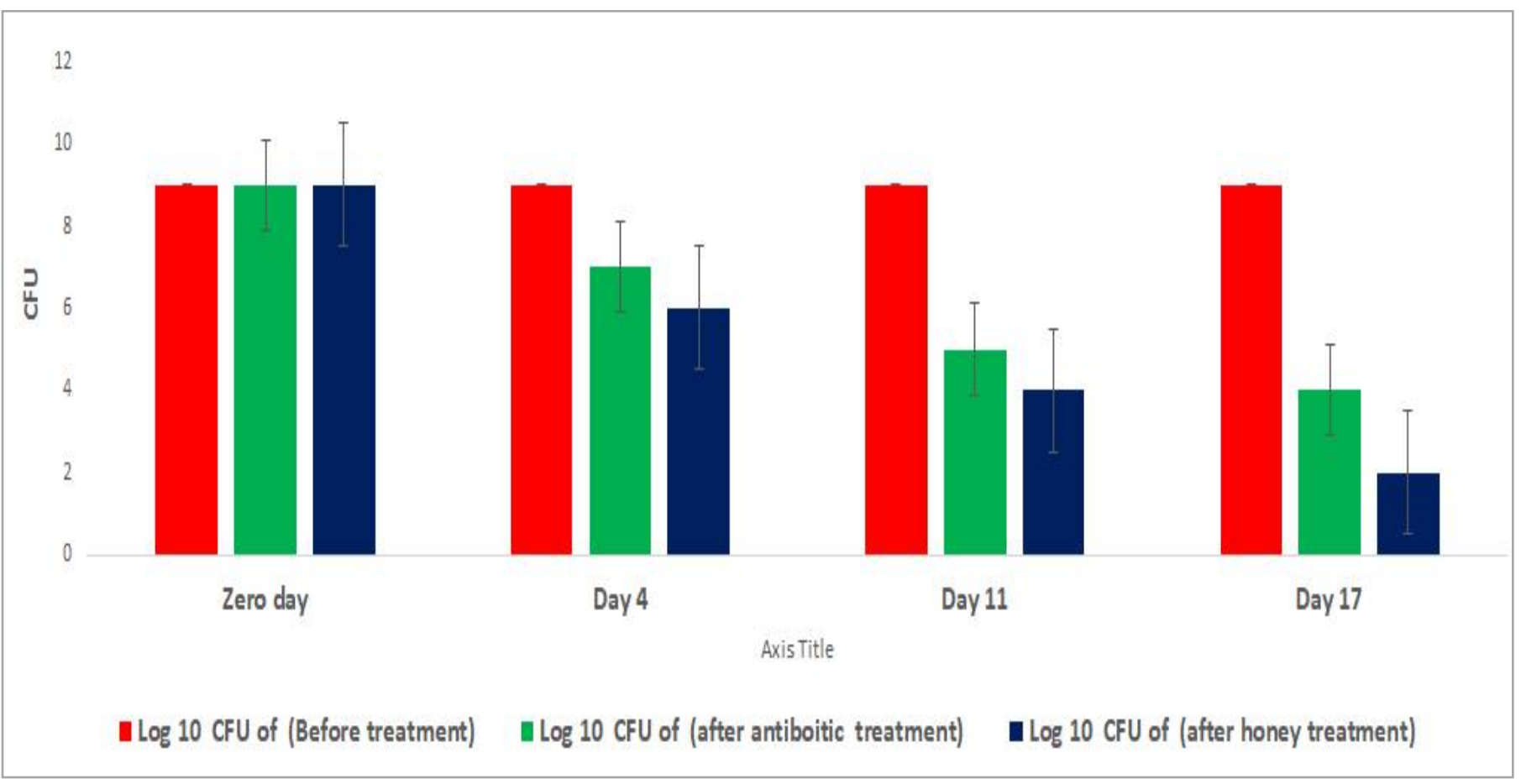

Figure 3. Total bacterial count $(\log 10)$ before and after treatment with Saudi Talh honey. 


\section{Discussion}

Honey dressing in the current clinical trial was more effective than regular saline and povidone-iodine dressing in the management of post-operative wounds and diabetic foot ulcers. The reasons for this outcome could be due to honey has growth factors, potent debriding effects, antibacterial activity, and anti-inflammatory. Also, honey is helpful for the removal of toxins through increases in lymph flow in the wound. It was reported in a clinical study on the positive effect of honey dressing in post-surgical wounds.

Moore et al., [15] found that honey has healing activity and a shorter time than all these treatments used in this aspect. Also, Wang et al. [16] stated that honey more effective, easy application, better outcome, and patients' satisfaction for the treatment of diabetic foot ulcers Moghazy et al., [17] studded honey in clinical and cost-effectiveness in the treatment of post-operative and diabetic foot ulcers. In the current study, patients were good assessment and the study continued for 3 years. It was observed that it was appropriate for treated subjects that belonged to a lower socio-economic class, and that wound healing was observed only clinically, and isolation of microorganisms to estimate the total bacterial count. It was observed that honey stains the wound margins and it has a specific odour and colour. Bowler et al., [18] showed a lack of facilities belonged to lower socioeconomic class. It was clear that there was a significant rededication after using natural honey also rededication in the dressing budget reached $75 \%$ as well as patients' pain levels as evidenced by the use of the Visual Analog Scale. Although effectiveness of honey dressing in post-operative wounds and diabetic foot ulcers were under taken in several studies. On the other hand, many clinicians are still hesitant to use it in their clinical practice [3]. These results may be due to many reasons, such as lack of a clear level one proof of the positive effect of honey on wound ulcers, personal bias, and lack of knowledge of the full spectrum of honey antibacterial and wound healing ability [3]. Efficient honey dressing agent instead of traditional dressings in the treatment of diabetic foot ulcer patients determined in our results of this study in accordance with the findings of Imran et al., [1]. Shukrimi et al., [19] reported that honey was a safe alternative treatment for Wagner grade II diabetic foot ulcers. Cooper [20] stated that debriding, anti-inflammatory characteristics, the ability to promote angiogenesis and the stimulation of healing were included as therapeutic claims.

Results of the current investigation using honey leads to wound healing due to its stimulation of inflammatory cytokines from monocytic cells these results confirmed by previous findings of Tonks et al., [21] who found that effective role in healing and tissue repair conducted out by monocytic cells. Also, honey able to stimulate leukocytes to release cytokines [21], which initiates the tissue repair process [22]. Honey also activates the immune response to infection [23], other aspects of the immune system [3], also
B- and T- lymphocyte proliferation and the action of phagocytes [24]. Honey triggers the production of antibodies [25]. It has the improvement of the immune system and antibacterial activity [26]. Many authors as Mandal and Mandal [27], Hegazi et al., [2,9] and Kalakattawi et al., [28] detected broad-spectrum antibacterial activity of honey.

This investigation was conducted to evaluate the pro-inflammatory cytokines IFN- $\gamma$ and interleukin (IL) $-1 \beta$, and IL-6) at baseline and after 6 weeks of the end of the study using enzyme-linked immunosorbent assays. Results are shown as the mean \pm standard error in pictograms per milliliter. All patients with diabetic foot in the group treated with honey had significantly higher cytokine concentrations vs control Group using the traditional treatment. Subjects at the end of the experiment were significantly reduced (Figure 2). Similar findings showed an altercation of various cytokines in patients enduring diabetic foot ulcers [29]. Nuwa et al., [30] and Zubair and Ahmad [31] reported that the diabetic wound healing process can be accelerated by controlling cytokines levels.

In the present study, the total bacterial count was $8 \times 10^{9}$ at zero time, then gradually reduced to reach $\left(9 \times 10^{4}\right)$ after the application of traditional therapy and $\left(9 \times 10^{2}\right)$ in honey treatment after $17^{\text {th }}$ days post-treatment. This result proved significant antibacterial activities of honey, which is probably attributed to

The antibacterial activity of honey refers to many factors as observed with many authors [32-35]. The antibacterial activity of different honey was previously studied by and Hegazi et al., [2,9] and Cooper [29]. In any wound, the abundance and variability of microorganisms would be influenced by various factors such as type of wound, depth, location and quality, tissue level and immune response of the host [18]. A wide variety of microorganisms' growth in the wound becomes optimal if the involved tissue devitalized, contaminate, colonize, and the low host immune response [18]. Staphylococcus epidermidis, micrococci exposure as one of the members of the normal skin microflora of devitalized tissue associated which leading a slowly chronic wound healing to facilitate colonization and establishment of a wide variety of endogenous microorganisms. Sufficiently hypoxic in wounds will not reduce the susceptible environment to a wide variety of endogenous anaerobic bacterial colonization [36]. Whereas minor wound healing may provide sufficient time for a relatively low number of skin contaminants to reside [37], the continued exposure of damaged tissue tissue correlated with slowly healing chronic wounds is likely to promote colonisation and the establishment of a wide range of endogenous microorganisms [38].

\section{Conclusion}

The findings of the current investigation may be concluded that honey dressing plays a significant role in healing ulcers and time for healing compared to conventional 
dressing substances in diabetic foot ulcers. Honey has antimicrobial activity and its growth factors influence healing. As well as being a natural product, honey has a variable in its chemical composition and biological activities.

\section{References}

1.Imran M, Hussain MB, Baig M. A randomized, controlled clinical trial of honey-impregnated dressing for treating diabetic foot ulcer. Journal of the College of Physicians and Surgeons Pakistan. 2015;25(10):721-725.

2.Hegazi AG, Al Guthami FM, Al Gethami AF, Abd Allah FM, Saleh AA, Fouad EA. Potential antibacterial activity of some Saudi Arabia honey. Veterinary world. 2017;10(2):233-237.

3.Yaghoobi R, Kazerouni A, Kazerouni O. Evidence for clinical use of honey in wound healing as an anti-bacterial, anti-inflammatory anti-oxidant and anti-viral agent: a review. Jundishapur journal of natural pharmaceutical products.2013;8(3):100-104.https://doi.org/10.17795/jjnp p-9487

4.Saha A, Chattopadhyay S, Azam M, Sur PK. The role of honey in healing of bedsores in cancer patients. South Asian journal of cancer. 2012;1(2):66-71.https://doi.org /10.4103/2278-330X.103714

5.Vijaya KK, Nishteswar K. Wound healing activity of honey: A pilot study. Ayu. 2012 Jul;33(3):374-377. https://doi.org/10.4103/0974-8520.108827

6.Brölmann FE, Ubbink DT, Nelson EA, Munte K, Van Der Horst CM, Vermeulen H. Evidence-based decisions for local and systemic wound care. British Journal of surgery. 2012 Sep;99(9):1172-1183.

7.Ramirez-Acuña JM, Cardenas-Cadena SA, Marquez-Salas PA, Garza-Veloz I, Perez-Favila A, Cid-Baez MA, Flores-Morales V, Martinez-Fierro ML. Diabetic foot ulcers: Current advances in antimicrobial therapies and emerging treatments. Antibiotics. 2019 Dec;8(4):193. https://doi.org/10.3390/antibiotics8040193

8.Clark WC. Pain Measurement. Susanne Bennett Clark $\mathrm{PhD}$, in Pain Management Secrets (Third Edition) ; 2009; Argoff CE. and McCleane G. Pain management secrets. 3rd ed. / [edited by] Charles E. Argoff, Gary McCleane. p.. WL 18.2 P144 2010] RB127.P33239 20106160.0472 $-\mathrm{dc} 22$

9.Hegazi AG, Al Guthami FM, Al Gethami AFM, Fouad EA, Abdou AM. Antibacterial activity and characterization of some Egyptian honey of different floral origin. Bulgarian Journal of Veterinary Medicine. 2019; 1-13.

10.Louveaux J, Maurizio A, Vorwhol G. Methods of melissopalynology. Bee World. 1978 ;59:139-157.

11.Quinn PJ, Carter ME, Markey B, et al. Clinical veterinary microbiology. London: Wolfe Publishing Ltd; 1994.

12.Clarke ML, Burton RL, Hill AN, Litorja M, Nahm MH, Hwang J. Low-cost, high-throughput, automated counting of bacterial colonies. Cytometry. Part A: the journal of the International Society for Analytical Cytology.
2010;77(8):790-797.

13.Mansfield KG, Fox JG. Chapter 16-Bacterial Diseases. The Common Marmoset in Captivity and Biomedical Research. American College of Laboratory Animal Medicine. 2019; 265-287.

14.Hegazi AG, Al Guthami FM, Al Gethami AF, El Fadaly HA. Beneficial effects of capparis spinosa honey on the immune response of rats infected with toxoplasma gundii. Journal of pharmacopuncture. 2017 Jun;20(2):112.

15.Moore OA, Smith LA, Campbell F, Seers K, McQuay HJ, Moore RA. Systematic review of the use of honey as a wound dressing. BMC complementary and alternative medicine. 2001 Dec 1;1(1):2.

16.Wang C, Guo M, Zhang N, Wang G. Effectiveness of honey dressing in the treatment of diabetic foot ulcers: A systematic review and meta-analysis. Complementary Therapies in Clinical Practice. 2019;34:123-131.

17. Moghazy AM, Shams ME, Adly OA, Abbas AH, El-Badawy MA, Elsakka DM, Hassan SA, Abdelmohsen WS, Ali OS, Mohamed BA. The clinical and cost effectiveness of bee honey dressing in the treatment of diabetic foot ulcers. Diabetes Research and Clinical Practice. 2010; 89(3):276-281.

18.Bowler PG, Duerden BI, Armstrong DG. Wound microbiology and associated approaches to wound management. Clinical microbiology reviews. 2001;14 (2):244-269.

19.Shukrimi A, Sulaiman AR, Halim AY, Azril A. A comparative study between honey and povidone iodine as dressing solution for Wagner type II diabetic foot ulcers. Medical Journal of Malaysia. 2008;63:44-6.

20.Cooper R. Honey for wound care in the 21 st century. Journal of Wound Care. 2016;25(9): 544-52

21.Tonks AJ, Cooper RA, Jones KP, Blair S, Parton J, Tonks A. Honey stimulates inflammatory cytokine production from monocytes. Cytokine. 2003 Mar 7;21(5):242-247.

22.Tisoncik JR, Korth MJ, Simmons CP, Farrar J, Martin TR, Katze M G. Into the eye of the cytokine storm. Microbiology and molecular biology reviews: MMBR. 2012;76(1):16-32.

23.Zhang JM, An J. Cytokines, inflammation, and pain. International anesthesiology clinics. 2007;45(2):27-37. https://doi.org/10.1097/AIA.0b013e318034194e

24.Abd Al Saheb ZA. The effects of honey on phagocytic activity against Staphylococcus aureus. Journal of Kerbala University. 2011;9 (3): 335-339.

25.Al-Waili NS, Haq A. Effect of honey on antibody production against thymus-dependent and thymus-independent antigens in primary and secondary immune responses. Journal of Medicinal Food. 2004;7(4):491-494.doi:10.1089/jmf.2004.7.491

26.Almasaudi SB, Al-Nahari A, Abd El-Ghany E, Barbour E, Al Muhayawi SM, Al-Jaouni S, Azhar E, Qari M, Qari YA, Harakeh S. Antimicrobial effect of different types of honey on Staphylococcus aureus. Saudi journal of 
biological sciences. 2017;24 (6):1255-1261.

27. Mandal MD, Mandal S. Honey: its medicinal property and antibacterial activity.Asian Pacific journal of tropical biomedicine.2011;1(2):154-160.https://doi.org/10.1016/S 2221-1691(11)60016-6

28.Kalakattawi A, Al Attas SG, Edris S, Abdel Azeiz AZ, AlGuthami AF, Hegazi AG, Almasaudi SB, Al-Hindi RR, Bahieldin A. In vitro Anti-candida Activity of Different Saudi Honeys and Honey Mixed with Taifi Rose Oil. Biosciences Biotechnology Research Asia. 2019;16(4): 779-787.

29. Cooper R. The use of honey in diabetic foot ulcers. The Diabetic Foot Journal. 2017;20(3): 154-9.

30.Nuwa MS, Alivian GN, Utama JEP, Fatarona A. Effectiveness of honey in treatment of diabetic foot ulcer: A systematic review. $8^{\text {th }}$ International Nursing Conference "Education, Practice and Research Development in Nursing; 2018.

31.Zubair M, Ahmad J. Role of growth factors and cytokines in diabetic foot ulcer healing: A detailedreview. Reviews in Endocrine and Metabolic Disorders. 2019;20:207-217.

32.Molan PC, Russell KM. Non peroxide antibacterial activity in some New Zealand honey. Journal of Apicultural Research. 1988; 27: 62-67.

33.Nour ME. Some factors affecting quality of Egyptian honeys (Thesis), Faculty of Agriculture, Cairo University; 1988.

34.Brady N, Molan P, Bang L. A survey of non-manuka New Zealand honeys for antibacterial and antifungal activities. Journal of apicultural research. 2004 Jan 1;43(2):47-52.

35. Mercan N, Guvensen A, Celik A, Katircioglu H. Antimicrobial activity and pollen composition of honey samples collected from different provinces in Turkey. Natural Product Research. 2007;21:187-195.

36. Hentges D. Anaerobes as normal flora. In: Finegold S M, George W L, editors. Anaerobic infections in humans. San Diego (Calif): Academic Press, Inc. ;1989. pp.37-53.

37.Duerden B I. Virulence factors in anaerobes. Clinical Infectious Diseases.1994;18:253-259.

38.Brook I, Frazier EH. Aerobic and anaerobic microbiology of chronic venous ulcers. International Journal of Dermatology.1998; 37:426-428. 